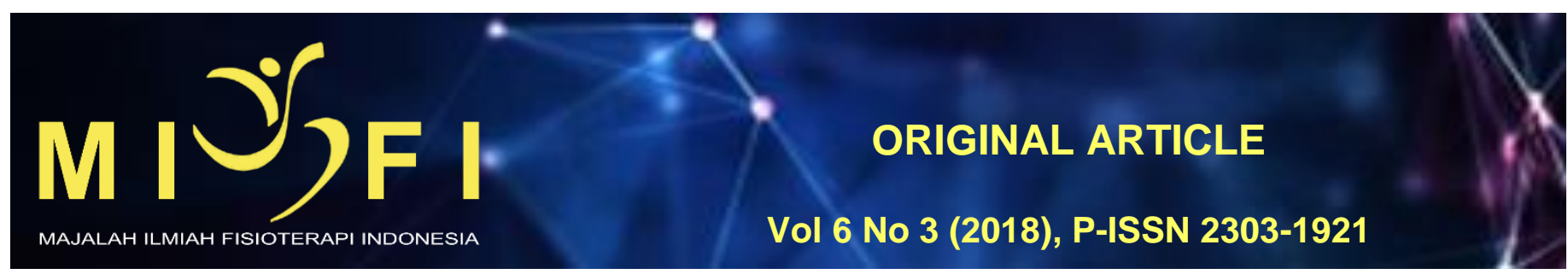

PERBEDAAN KELUHAN MUSKULOSKELETAL ANTARA PEMAHAT KAYU DAN PELUKIS DI UBUD

\author{
Ni Kadek Citra Patmala ${ }^{1}$, Anak Ayu Nyoman Trisna Narta Dewi ${ }^{2}$, I Made Muliarta ${ }^{3}$ \\ 1,2Program Studi Fisioterapi Fakultas Kedokteran Universitas Udayana, Denpasar Bali \\ ${ }^{3}$ Bagian IImu Faal Fakultas Kedokteran, Universitas Udayana, Denpasar Bali \\ citrapatmala75@gmail.com
}

\begin{abstract}
ABSTRAK
Aktivitas kerja dapat menimbulkan sakit, nyeri, pegal- pegal dan gangguan lainnya pada sistem otot yang merupakan salah satu keluhan muskuloskeletal. Pemahat kayu dan Pelukis adalah pekerja yang masih dominan bekerja dengan sistem manual. Hal yang ingin dicapai pada penelitian adalah untuk mengetahui perbedaan keluhan muskuloskeletal antara pemahat kayu dan pelukis dan membuktikan kebenaran hipotesis penelitian yang sudah dirumuskan. Penelitian ini adalah penelitian observasi, analitik kategorik tidak berpasangan dengan pendekatan potong lintang. Teknik pengambilan sampel pada penelitian ini adalah simpel random sampling. Sampel penelitian ini berjumlah 96 orang yang dibagi menjadi 2 kelompok, yaitu kelompok Pemahat kayu dan kelompok Pelukis. Pengumpulan data dilakukan dengan cara pengisian kuesioner Nordic Body Map. Uji statistik menggunakan Chi- Square dan Independent $T$-test. Hasil penelitian menunjukan adanya perbedaan keluhan muskuloskeletal yang bermakna pada pemahat kayu dan pelukis, dengan nilai rerata pemahat kayu $40,7 \pm 5,3$ dan nilai rerata pelukis $43,2 \pm 6,2$, sehingga $p=0,038(p<0,05)$, maka terdapat perbedaan keluhan muskuloskeletal antara pemahat kayu dan pelukis, dimana keluhan muskuloskeletal pada pelukis lebih besar dari pemahat kayu. Analisis perbedaan keluhan muskuloskeletal setiap ekstremitas mendapatkan hasil pada ekstremitas atas dengan nilai rerata pemahat kayu $17,1 \pm 0,38$, dan nilai rerata pelukis 17,3 $\pm 2,5$, sehingga $p=0,692(p>0,05)$, pada trunkus dengan nilai rerata pemahat kayu $8,3 \pm 1,69$ dan nilai rerata pelukis $10,5 \pm 2,50$, sehingga $p=0,000(p<0,05)$ dan pada ekstremitas bawah dengan nilai rerata pemahat kayu 15,1 $\pm 2,69$ dan nilai rerata pelukis $15,1 \pm 3,33$, sehingga $p=0,973(p>0,05)$. Dari hasil analisis keluhan muskuloskeletal setiap ekstremitas pada pemahat kayu dan pelukis maka dapat disimpulkan bahwa terdapat perbedaan keluhan muskuloskeletal yang bermakna antara pemahat kayu dan pelukis pada trunkus dan tidak terdapat perbedaan keluhan muskuloskeletal yang bermakna antara pemahat kayu dan pelukis pada ekstremitas atas dan ekstremitas bawah.

Kata Kunci: keluhan muskuloskeletal, nordic body map, pemahat kayu, pelukis
\end{abstract}

\title{
DIFFERENCES MUSCULOSKELETAL DISORDER BETWEEN WOOD CARVERS AND PAINTERS IN UBUD
}

\section{ABSTRACT}

Work activity can cause pain, pain, stiffness and other disorders of the muscular system which is one of the musculoskeletal complaints. Wood carvers and painters are workers who still dominant work with the manual system. The purpose of this study was to know the difference of musculoskeletal disorder between woodcarvers and painters and to justify the hypothesis of purpose that has been formulated.This research was observational research, categorical analytics unpaired with cross sectional approach. Sampling technique in this research was simple random sampling. The sample of this study amounted to 96 people divided into 2 groups, namely groups of wood carvers and painters. Data collection was done by filling the Nordic Body Map questionnaire. Statistical test using Chi-Square and Independent T-test. The results showed significant differences in musculoskeletal disorder on wood carver and painter, with woodcarvers mean value of 40,7 $\pm 5,3$ and painters mean value of $43,2 \pm 6,2$, so $p=0,038(p<0,05)$, then there are differences in musculoskeletal disorder among woodcarvers and painters, where musculoskeletal disorders at greater painter than woodcarver. Analysis of the difference each extremity musculoskeletal disorders in the upper extremities get results with woodcarvers mean value of $17.1 \pm 0.38$ and painters mean value of $17,3 \pm 2,5$, so $p=0,692$ ( $p>0,05$ ), on the trunk with woodcarvers mean value of $8,3 \pm 1,69$ and painters mean value of $10,5 \pm 2,50$, so $p=0,000$ $(p<0,05)$ and in the lower extremities with woodcarvers mean value of $15,1 \pm 2,69$ and the average value of the painters $15.1 \pm 3.33$, so $p=0.973$ ( $p>0.05$ ). The results of the analysis of each extremity musculoskeletal disorders in woodcarvers and painters, it can be concluded that there are significant differences in musculoskeletal disorder among woodcarvers and painters on the trunk and there are no significant differences in musculoskeletal disorder among woodcarvers and painters in the upper extremities and the lower extremities.

Keywords: muskuloskeletal disorder, Nordic body map, wood carver, painter 


\section{PENDAHULUAN}

Pekerjaan bersifat manual yang dikerjakan oleh manusia memerlukan kekuatan dan ketahanan tubuh dalam menyelesaikan pekerjaannya. Sakit pada bagian tubuh tertentu disebabkan oleh sikap kerja yang salah yang berkaitan dengan masalah ergonomi ${ }^{4}$.

Kerajinan pahat kayu banyak diproduksi oleh industri rumah tangga yang masih menggunakan alat yang sederhana dengan kapasitas produksi yang tidak terlalu besar. Pada seni pahat kayu terdapat banyak sekali motifmotif dan seringkali motif tersebut merupakan ciri khas dari berbagai daerah. Pembuatan sebuah karya seni pahat kayu membutuhkan sebuah keterampilan yang khusus, kesabaran, ketelitian, dan konsentrasi yang penuh agar tidak terjadi kesalahan dalam pembuatan pahatan. Sama halnya dengan melukis pengerjaan lukisan memerlukan waktu yang tidak singkat, namun tergantung pada tingkat kerumitan suatu lukisan. Pelukis setidaknya memerlukan waktu yang lebih banyak untuk menghasilkan lukisan yang sesuai dengan imajinasi atau pesanan pelanggan8.

Keluhan pada sistem otot berupa nyeri, kaku, pegal- pegal dan lainnya seperti pada saraf pembuluh darah, tulang, tendon, legamen dan lainnya dapat disebabkan oleh aktivitas kerja, keluhan tersebut merupakan contoh keluhan muskuloskeletal 3,2 .

\section{METODE PENELITIAN}

Jenis penelitian yang dipakai adalah observasional dengan pendekatan potong lintang, di mana sampel dibedakan menjadi dua kelompok yaitu pemahat kayu dan pelukis. Pengambilan sampel dengan teknik memberikan peluang yang sama kepada seluruh populasi untuk menjadi sampel. Populasi target pada penelitian ini meliputi pemahat kayu dan pelukis di Kabupaten Gianyar, dengan populasi terjangkau meliputi pemahat kayu dan pelukis di Kecamatan Ubud. Perhitungan besar sampel dihitung berdasarkan rumus besar sampel analitik komparatif tidak berpasangan, dengan jumlah total sampel sebesar 96 orang yang terdiri dari 48 orang pemahat kayu dan 48 orang pelukis. Sampel yang terpilih dalam penelitian adalah sampel yang sudah memenuhi kriteria, b. Bekerja dengan posisi duduk, c. Mampu memahami intruksi dalam penelitian, d. Bekerja > 4 jam perhari, e. Bersedia menjadi sampel dalam penelitian ini. Untuk mengukur besar keluhan muskuloskeletal pada pemahat kayu dan pelukis digunakan kuesioner Nordic Body Map.

\section{HASIL PENELITIAN}

Tabel 1. Distribusi Data Sampel Berdasarkan Usia Pada Pemahat Kayu Dan Pelukis

\begin{tabular}{ccccc}
\hline \multirow{2}{*}{ Karakteristik } & \multicolumn{2}{c}{ Pemahat Kayu } & \multicolumn{2}{c}{ Pelukis } \\
\cline { 2 - 4 } & $\mathbf{n}$ & $\begin{array}{c}\text { Rerata } \pm \\
\text { Simpang Baku }\end{array}$ & $\mathbf{n}$ & $\begin{array}{c}\text { Rerata } \pm \\
\text { Simpang Baku }\end{array}$ \\
\hline Usia & 48 & $45,0 \pm 6,3$ & 48 & $47,9 \pm 7,7$ \\
\hline
\end{tabular}

Dari Tabel 1. menunjukkan bahwa subjek penelitian kelompok pemahat kayu memiliki rerata usia 45,0 tahun dan kelompok pelukis memiliki rerata usia 47,9 tahun.

Tabel 2. Distribusi Data Sampel Berdasarkan Keluhan Muskuloskeletal Pada Ekstremitas Atas, Trunkus, Ekstremitas Bawah

\begin{tabular}{cccc}
\hline & \multicolumn{2}{c}{ Keluhan Muskuloskeletal } & \\
\cline { 2 - 3 } & Pemahat & Pelukis & \\
\cline { 2 - 3 } & Rerata \pm & Rerata \pm & $\mathbf{p}$ \\
& Simpang Baku & Simpang Baku & \\
\hline Ekstremitas Atas & $17,1 \pm 0,38$ & $17,3 \pm 2,52$ & 0,692 \\
Trunkus & $8,3 \pm 1,69$ & $10,5 \pm 2,50$ & 0,000 \\
Ekstremitas Bawah & $15,1 \pm 2,69$ & $15,1 \pm 3,33$ & 0,973 \\
\hline
\end{tabular}

Dari Tabel 2. menunjukkan bahwa subjek penelitian memiliki rerata keluhan muskuloskeletal pada ekstremitas atas pada pemahat yaitu $17,1 \pm 0,38$ dan pada pelukis $17,3 \pm 2,52$, keluhan muskuloskeletal pada trunkus pada pemahat yaitu $8,3 \pm 1,69$ dan pada pelukis $10,5 \pm 2,50$, dan keluhan muskuloskeletal pada ekstremitas bawah pada pemahat yaitu $15,1 \pm 2,69$ dan pada pelukis $15,1 \pm 3,33$.

Tabel 3. Uji Normalitas dan Homogenitas

\begin{tabular}{cccc}
\hline \multirow{2}{*}{ Skor Keseluruhan } & \multicolumn{2}{c}{ Shapiro- Wilk Test } & Levene's Test \\
\cline { 2 - 3 } & Statistik & $\mathrm{p}$ & $\mathrm{p}$ \\
\hline Pemahat Kayu & 0,971 & 0,267 & \multirow{2}{*}{0,250} \\
\hline Pelukis & 0,968 & 0,208 & \\
\hline
\end{tabular}

Tabel 3. menunjukkan hasil dari uji normalitas dan homogenitas, hasil dari uji normalitas dengan nilai pada pemahat kayu $p=0,971$ dan nilai pada pelukis $p=0,968$, sehingga $p>0,05$ maka distribusi data normal. Hasil dari uji homogenitas dengan nilai $p=0,250$, sehingga $p>0,05$ maka data berasar dari kelompok yang memiliki varian homogen.

Tabel 4. Keluhan Muskuloskeletal Pada Pemahat Kayu Dan Pelukis Menggunakan Chi- Square

\begin{tabular}{cccccccc}
\hline & \multicolumn{3}{c}{ Perbedaan Keluhan Muskuloskeletal } & \multicolumn{2}{c}{ Total } & \multirow{2}{*}{ p } \\
\cline { 2 - 6 } & \multicolumn{3}{c}{ Rendah } & Sedang & & & \\
& $\mathbf{F}$ & $\%$ & $\mathbf{F}$ & $\%$ & $\mathbf{N}$ & $\%$ & \\
\hline Pemahat Kayu & 44 & 91,6 & 4 & 8,4 & 48 & 100 & \multirow{2}{*}{0,271} \\
Pelukis & 40 & 83,4 & 8 & 16,6 & 48 & 100 & \\
Jumlah & 84 & 87,5 & 12 & 12,5 & 96 & 100 &
\end{tabular}


Berdasarkan Tabel 4. dapat dilihat bahwa pada pemahat yang memiliki keluhan muskuloskeletal dengan tingkat rendah yaitu sebanyak 44 orang $(91,6 \%)$ dan dengan tingkat sedang sebanyak 4 orang $(8,4 \%)$ dan pada pelukis yang memiliki keluhan muskuloskeletal dengan tingkat rendah yaitu sebanyak 40 orang yaitu (83,4\%) dan dengan tingkat sedang sebanyak 8 orang (16,6\%).

Tabel 5. Keluhan Muskuloskeletal Pada Pemahat dan Pelukis Menggunakan Uji Independent T-test

\begin{tabular}{ccc}
\hline & \multicolumn{2}{c}{ Keluhan Muskuloskeletal } \\
\cline { 2 - 3 } & Rerata \pm Simpang Baku & $\mathbf{p}$ \\
\hline Pemahat & $40,7 \pm 5,3$ & 0,038 \\
Pelukis & $43,2 \pm 6,2$ & \\
\hline
\end{tabular}

Dari Tabel 5. menunjukkan bahwa keluhan muskuloskeletal secara keseluruhan pada pemahat yaitu dengan rerata $40,7 \pm 5,3$ dan pada pelukis $43,2 \pm 6,2$, dihasilkan nilai $p$ sebesar 0,038 sehingga $p<0,05$, maka kesimpulan yang didapatkan bahwa terdapat perbedaan keluhan muskuloskeletal yang bermakna pada pemahat dan pelukis.

\section{DISKUSI}

Karakteristik sampel pada penelitian ini yaitu dibagi menjadi kelompok 1 dan kelompok 2, sampel berjenis kelamin laki- laki dengan jumlah total sampel sebanyak 96 orang dan terdiri dari 2 kelompok, dimana masing- masing kelompok berjumlah 48 orang, kelompok 1 adalah kelompok pemahat kayu sebanyak 48 orang dan kelompok 2 adalah kelompok pelukis sebanyak 48 orang.

Berdasarkan usia menunjukkan bahwa rerata usia sampel penelitian kelompok 1 memiliki rerata 47,9 tahun dan kelompok 2 memiliki rerata usia 45,0 tahun. Dengan usia termuda 35 tahun dan usia tertua 60 tahun. Usia menjadi salah satu faktor yang mempengaruhi terjadinya keluhan muskuloskeletal ${ }^{3,1}$.

Berdasarkan rerata keluhan muskoloskeletal pada ekstremitas atas pada pemahat yaitu 17,1 $\pm 3,0$ dan pada pelukis $17,3 \pm 2,5$, keluhan muskuloskeletal pada trunkus pada pemahat yaitu $8,3 \pm 1,6$ dan pada pelukis $10,5 \pm 2,5$ dan keluhan muskuloskeletal pada ekstremitas bawah pada pemahat yaitu 15,1 $\pm 2,6$ dan pada pelukis $15,1 \pm 3,3$.

Sakit di bagian tubuh atas atau kepala yang terdiri dari sakit di leher bagian atas adalah sebesar 2,80 \%, dan di leher bagian bawah adalah sebesar 3,48 \%. Sakit di tangan kiri adalah sebesar (3,61\%) dan tangan kanan adalah sebesar $(5,48 \%)$ hal ini diakibatkan oleh karena pekerjaannya memerlukan ke dua tangan, sakit di bagian bahu sebesar $(3,48 \%)$ dan sakit di bagian lengan atas. Pada kaki paling dominan terdapat di bagian lutut $(4,01 \%)$, di pergelangan kaki sebesar $(3,88 \%)$, dan di paha $(3,74 \%)^{7}$.

Hasil penelitian setelah dilakukan uji Independent T-Test didapatkan nilai p sebesar 0,038 sehingga $\mathrm{p}<0,05$, maka dapat disimpulkan bahwa adanya perbedaan keluhan muskuloskeletal yang bermakna pada Pemahat dan Pelukis. Berdasarkan rerata keluhan muskuloskeletal secara keseluruhan didapatkan bahwa rerata keluhan pada Pelukis lebih besar dari rerata keluhan Pemahat kayu, hal ini dapat diartikan bahwa keluhan muskuloskeletal pada Pelukis lebih besar daripada keluhan muskuloskeletal pada Pemahat kayu. Sikap kerja antara Pemahat kayu dan Pelukis menjadi faktor resiko terjadinya keluhan muskuloskeletal seperti contoh durasi kerja, beban kerja, dan stress saat bekerja.

Hasil penelitian setelah dilakukan uji Independent T-Test diperoleh nilai p sebesar 0,038 sehingga $p<0,05$, maka dapat disimpulkan bahwa adanya perbedaan keluhan muskuloskeletal yang bermakna pada Pemahat dan Pelukis. Berdasarkan rerata keluhan muskuloskeletal secara keseluruhan didapatkan bahwa rerata keluhan pada Pelukis lebih besar dari rerata keluhan Pemahat kayu, hal ini dapat diartikan bahwa keluhan muskuloskeletal pada Pelukis lebih besar daripada keluhan muskuloskeletal pada Pemahat kayu. Sikap kerja antara Pemahat kayu dan Pelukis menjadi faktor resiko terjadinya keluhan muskuloskeletal seperti contoh durasi kerja, beban kerja, dan stress saat bekerja.

Perbedaan keluhan muskuloskeletal pada trunkus antara Pemahat kayu dan Pelukis disebabkan oleh sikap kerja antara Pemahat kayu dan Pelukis, dimana pada saat Pemahat kayu memahat mereka lebih santai bisa bekerja sambal berbincang- bincang sesama pekerja dan mengikuti jam kerja yang sudah ditentukan. Sedangkan pelukis saat melukis akan melihat hasil lukisannya dari berbagai sudut pandang sebelum melanjutkan lukisannya, pelukis lebih berkonsentrasi untuk menyelesaikan lukisannya sebelum inspirasi untuk lukisannya hilang, sehingga Pelukis seringkali tidak mengikuti jam kerja yang sudah ditentukan. Duduk statis menjadi salah satu faktor resiko terjadinya keluhan muskuloskeletal, ini terbukti jika bekerja setelah 90-300 menit ${ }^{6,5}$.

Bekerja dengan posisi statis untuk durasi kerja yang lama akan menimbulkan keluhan muskuloskeletal, contohnya seperti low back pain. Dimana terjadinya spasme pada otot di sekitar leher, punggung, pinggang, dan lain sebagainya akibat otot mempertahankan posisi kerja dalam waktu yang lama.

Bekerja dengan posisi statis dengan waktu yang lama dapat menimbulkan adanya penyumbatan darah yang akan berdampak berkurangnya aliran darah, pasokan oksigen glukosa dalam darah dan menumpuknya asam laktat sebagai sisa hasil metabolism dan akan menimbulkan nyeri ${ }^{9}$.

\section{SIMPULAN}

Pada penelitian perbedaan keluhan muskuloskeletal pada Pemahat kayu dan Pelukis, dapat disimpulkan bahwa 1. Terdapat perbedaan keluhan muskuloskeletal yang bermakna antara Pemahat kayu dan Pelukis, dimana ratarata keluhan muskuloskeletal pada Pelukis lebih besar dari Pemahat kayu di Ubud. 2. Terdapat perbedaan keluhan muskuloskeletal yang bermakna pada trunkus antara Pemahat kayu dan Pelukis di Ubud. 3. Tidak terdapat perbedaan keluhan muskuloskeletal yang bermakna pada ekstremitas atas dan ekstremitas bawah antara Pemahat kayu dan Pelukis di Ubud. 
Keluhan muskuloskeletal pada Pemahat kayu dan Pelukis dapat digunakan sebagai referensi dan upaya preventif dalam mencegah terjadinya keluhan muskuloskeletal, penelitian selanjutnya lebih memperhatikan faktor faktor yang mempengaruhi penelitian termasuk mengontrol suhu lingkungan dimana sampel bekerja dan mengontrol shift kerja pada sampel, dan peneliti selanjutnya memberikan intervensi untuk menangani keluhan muskuloskeletal pada Pemahat kayu dan Pelukis.

\section{DAFTAR PUSTAKA}

1. Chaffin, D. B., dan Anderson, G. B. J. 1987. Occupational Biomechanics Edisi III. New York: John Wiley \& Sons.

2. Nurjanah, S. 2012. Hubungan Sikap Kerja Duduk Dengan Keluhan Muskuloskeletal Pada Pekerja Bagian Reaching PT. Delta Merlin Dunia Textile Kebakkramat Karanganyar. (Skripsi) Surakarta: Fakultas Kedokteran Universitas Sebelas Maret Surakarta.

3. OHSCOs (Occupational Health and Safety Council of Ontario). 2007. Prevention Musculoskeletal Tool Box. Ontario, USA.

4. Putri, D. W., dan Adhiarta, G. 2016. Perbaikan Stasiun Kerja Menurunkan Listrik Otot Dan Keluhan Muskuloskeletal Pada Pengrajin Ukir Kayu Di Desa Batuan Gianyar Bali. (E-jurnal) Denpasar: Fakultas Kedokteran Universitas Udayana.

5. Samara, D. 2004. Lama dan Sikap Duduk Sebagai Faktor Risiko Terjadinya Nyeri Pinggang Bawah. (E-jurnal) $J$ Kedokter Trisakti. Jakarta: Fakultas Kedokteran Trisakti.Vol.23 No.2.

6. Subagya, A. 2010. Pengaruh Stasiun Kerja Terhadap Keluhan Otot-Otot Skeletal Pekerja Laki-Laki Pada Kantor Adminitrasi Dokumen Building PT. Krakatau Steel Cilegon. (Skripsi) Surakarta: Fakultas Kedokteran Universitas Sebelas Maret.

7. Susihono, W. 2014. Evaluasi Beban Kerja Dan Keluhan Muskuloskeletal Pekerja Di Perusahaan Pengecoran Logam X Sistem Dapur Induksi. (E- jurnal) Seminar Nasional IENACO - 2014. Serang: Jurusan Teknik Industri Fakultas Teknik Universitas Sultan Ageng Tirtayasa.

8. Utami, D. D. 2014. Pengaruh Melukis Terhadap Kreativitas Seni Anak Usia Dini Di TK 02 Buran Tasikmadu Karanganyar Tahun 2013/2014. (Skripsi) Fakultas Keguruan Dan IImu Pendidikan Universitas Muhammadiyah Surakarta.

9. Utari, F. Y., Kalsum., dan Mahyuni, E. L. 2015. Hubungan Sikap Kerja Dengan Keluhan Musculoskeletal Pada Penyortir Tembakau Di Gudang Sortasi Tembakau Kebun Klumpang SUTK PTPN II Tahun 2015. (E-jurnal) Departemen Keselamatan dan Kesehatan Kerja FKM USU. 